\title{
CHARACTERIZATION OF FATIGUE UNDER THE AFFECTIVE DIMENSION OF THE PIPE SCALE REVIEWED IN WOMEN WITH BREAST NEOPLASIA UNDERGOING CHEMOTHERAPY TREATMENT
}

\section{${ }^{1}$ Cristina Albuquerque Douberin, ${ }^{2, *}$ Liniker Scolfild Rodrigues da Silva, ${ }^{3}$ Talita Munique de Melo Rodrigues, ${ }^{4}$ Edivaldo Bezerra Mendes Filho, ${ }^{5}$ Adriana Maria dos Santos, ${ }^{6}$ Taynan da Silva Cosntantino, ${ }^{7}$ Thayná da Silva Constantino, ${ }^{8}$ Evelim Paloma Figueira de Lima, ${ }^{9}$ Bruna Kathiely Meneses da Silva, ${ }^{10}$ Marília Guilherme Silva Guimarães, ${ }^{11}$ Mércia Santos de Lima, ${ }^{12}$ Leônidas Moreira do Valle Neto and ${ }^{13}$ Rayane Gomes de Barros}

${ }^{1}$ Nurse, Master in Nursing, University of Pernambuco/State University of Paraíba (UPE/UEPB), Recife, Pernambuco (PE)/Campina Grande, Paraíba (PB), Brazil. ${ }^{2}$ Nurse, Specialist in Obstetric Nursing in the Residency modality from the

Nossa Senhora das Graças College (FENSG)/University of Pernambuco (UPE). Public Health Officer from the Medical Sciences College (FCM)/UPE. Recife, Pernambuco (PE), Brazil. ${ }^{3}$ Nursing, Resident in the Program of Residence in Children Healthcare from the Institute of Integral Medicine Professor Fernando Figueiras (IMIP). Recife, Pernambuco (PE), Brazil. ${ }^{4}$ Doctor, Medical Sciences College (FCM)/University of Pernambuco (UPE). Recife, Pernambuco (PE), Brazil. ${ }^{5}$ Nurse, Olinda Foundation for Higher Education (FUNESO). Recife, Pernambuco (PE), Brazil. ${ }^{6}$ Nurse, Federal University of Pernambuco

(UFPE-CAV). Vitória de Santo Antão, Pernambuco (PE), Brazil. ${ }^{7}$ Nurse, Master in Physiology and Biochemistry by the

Federal University of Pernambuco (UFPE). Recife, Pernambuco (PE), Brazil. ${ }^{8}$ Nurse, Postgraduate student in Obstetric Nursing at IDE Colleg. Recife, Pernambuco (PE), Brazil. 9,10,11Nursing Academic, Brazilian University Center - UNIBRA. Recife, Pernambuco (PE), Brazil. ${ }^{12}$ Biologist, Escada College Teacher. Escada, Pernambuco (PE), Brazil. ${ }^{13}$ Nursing Academic, Brazilian University Center - UNIBRA. Recife, Pernambuco (PE), Brazil

\section{ARTICLE INFO}

Article History:

Received $29^{\text {th }}$ June 2020

Received in revised form

$10^{\text {th }}$ July 2020

Accepted $17^{\text {th }}$ August 2020

Published online $30^{\text {th }}$ September 2020

\section{Key Words:}

Fatigue; Health Impacts; Women; Breast

Neoplasms; Chemotherapy; Treatment.

*Corresponding author:

Liniker Scolfild Rodrigues da Silva

\begin{abstract}
Objective: This study aims to characterize fatigue in women with breast neoplasia submitted to chemotherapy treatment under the affective dimension of the Piper Scale - Reviewed. Materials and Methods: It was a descriptive, cross-sectional study with a quantitative approach and it was carried out in the Outpatient Unit of a specialized clinic in Mammary Pathology of the Pernambuco Cancer Hospital ( $\mathrm{PCH})$. The data collection procedure was carried out by signing the Free and Informed Consent Term (FICT) and later responded to the collection instrument at Piper's Fatigue Scale - Revised. Results: The results of the study revealed that the destructive characteristic of fatigue, presented higher mean (6.40), as well as higher level of fatigue (prevalence) felt by the patients. $25.6 \%$ of the women described their fatigue with the maximum value of the scale, that is, as this unpleasant. It was observed that 80 patients $(25.2 \%)$ outlined their fatigue as being more negative, thus marking the maximum extreme (ten) of the series. Conclusion: In view of this, it is necessary to have strategies to relieve the symptoms affected by the treatment.
\end{abstract}

Copyright (C) 2020, Cristina Albuquerque Douberin et al. This is an open access article distributed under the Creative Commons Attribution License, which permits unrestricted use, distribution, and reproduction in any medium, provided the original work is properly cited.

Citation: Cristina Albuquerque Douberin, Liniker Scolfild Rodrigues da Silva, Talita Munique de Melo Rodrigues et al. 2020. "Characterization of fatigue under the affective dimension of the pipe scale reviewed in women with breast neoplasia undergoing chemotherapy treatment", International Journal of Development Research, 10, (09), 40739-40742.

\section{INTRODUCTION}

Cancer is characterized by being a very diversified pathology, since it presents itself under innumerable nuances in terms of malignancy, location and causality. Therefore, it consists of a term used to designate a set of approximately 100 diseases with consequently divergent manifestations, treatments and prognoses (Silva, 2013). Cancer affects citizens of both sexes and can occur in different body locations, among them: lung, bladder, intestine, esophagus, mouth, cervix, breast, among others. Considering that the object of this research is derived from one of the most prevalent types of cancers in the female population, a special highlight will be given below on breast 
cancer. Breast cancer is the type of neoplasia originating from the epithelial cells that line the unit of the mammary lobe terminal duct (Lisbon, 2009). In terms of its epidemiology, breast cancer is the most frequent among women (Lamino, 2012 ), accounting for up to $23 \%$ of cases worldwide (Jemal et al., 2011), giving way only to lung cancer, when both sexes are considered (Cantinelli et al., 2006). Breast cancer treatment, in turn, is outlined by a few specific facets, which can be applied locally or systemically, as well as singly or in combination. Among the treatment modalities we have chemotherapy, which can be defined as the use of chemicals alone or in combination to kill malignant cells. It is also worth noting that it has palliative and curative cleats (Anjos, 2005). There are many symptoms caused by the chemotherapy treatment of cancer, including breast cancer, but fatigue is still little explored in the national literature, which makes its management and knowledge somewhat obscure. In this study, such symptom gained a prominent place and will serve as a guide for its design, since it is also one of the most reported by these patients. In order to identify, therefore, the presence of fatigue as a chemotherapeutic side effect in women with breast cancer, broadening its dissemination in the literature, a guiding question supported the interest in the study: What is the intensity of fatigue under the affective dimension of the Piper Scale - Reviewed in women with breast neoplasms submitted to chemotherapy treatment? And the answer to this question was if it was the objective of this study.

\section{MATERIALS AND METHODS}

It was a descriptive, transversal study with quantitative approach that was carried out in the Outpatient Unit of a specialized clinic in Mammary Pathology of the Pernambuco Cancer Hospital (PCH), from September to November 2015. $\mathrm{PCH}$ is characterized as an institution that began its activities in a philanthropic manner on November 9, 1945. Since its creation until today, it has become a reference in its field of action in the North and Northeast of Brazil and, throughout its trajectory; it plays the role of assistance to cancer carriers, as well as that of informing the population about the importance of prevention of this offense. As of April 10, 2007, the state of Pernambuco was taken under control, serving more than half of the cancer patients in that state. The sample was calculated based on the estimated proportion, since it was intended to identify it for the quantitative of women with breast cancer undergoing chemotherapy treatment, who feel fatigue. Considering that the monthly average of patients with breast neoplasia in chemotherapy treatment in $\mathrm{PCH}$ was $1800(\mathrm{~N})$ and some constant statistical values, such as the $95 \%$ confidence level $(z=1.96)$ and the error $(e)$ or $(d)$ of $5 \%$, we obtained a sample (n) of 317 patients, taking as reference a finite population. In this case, the sample proportion (p) and its complement (q) were taken with the same value of 0.5 , which provides the largest possible sample for the population considered for the calculation of the sample, from the formula below:

$$
\mathrm{n}=\quad \begin{gathered}
\mathrm{Z}^{2} \cdot \mathrm{p} \cdot \mathrm{q} \cdot \mathrm{N} \\
\mathrm{d}^{2}(\mathrm{~N}-1)+\mathrm{Z}^{2} \cdot \mathrm{p} \cdot \mathrm{q}
\end{gathered}
$$

As inclusion criteria, we considered female patients with breast cancer, in outpatient chemotherapy treatment in $\mathrm{PCH}$, aged 18 years or older and with communication skills for reading and writing comprehension.
As exclusion criteria, we had female patients in a modality of treatment different from chemotherapy. Regarding the variables, fatigue corresponds to the qualitative and studydependent variable, which was evaluated through the following instrument: Piper Fatigue Scale - Revised (PIPER). This is a multidimensional self-reporting instrument for assessing fatigue, which was developed by Piper et al. in 1998 with reference to the Piper Fatigue Scale (PFS), proposed by Piper et al. in 1989, and which had recent validation for the Portuguese language in 2009 (Mota; Pimenta; Piper, 2009). The original version of Piper is composed of 27 items, but the Brazilian version (which will be discussed here) is composed of 22, among which there are three main dimensions: behavioral dimension (items 2 to 7 ), affective dimension (items 8 to 12) and sensory/psychological dimension (items 13 to 23). Among these, the affective dimension will be analyzed here. Regarding its gradation, it can be said that for each dimension evaluated, it has scores from 0 to 10 , being established as cut point the score 4. For the fatigue to be clinically significant, therefore, the score must be higher than 4. The average of all items corresponds to the total score and each dimension has its scores calculated by the average of the items contained in them.

The data collected was first inserted in spreadsheets in Microsoft Excel software and then transferred and analyzed using a quantitative descriptive approach using the Statistical Package for Social Science (SPSS) software version 21.0. For the characterization of fatigue, the symptom was analyzed from the perspective of its absolute and percentage frequencies, taking into account the identifying cutoff point of its presence as that recommended by score 4 (if the score is equal to or less than 4 , it will mean no fatigue; however, if it is more than 4, fatigue will be present) (NCCN, 2011; MansanoSchlosser; Ceolim, 2014). The description and analysis of the affective dimension (items 8 to 12) of the Piper Fatigue Scale Revised were carried out, taking into account the means of the scores by items inherent to it. The data collection procedure was carried out as follows: the Free and Informed Consent (FICT) was given, read and explained to each of the 317 women at the time they were performing the chemotherapy at the PCH outpatient clinic. When they agreed to participate in the survey, they signed it demonstrating their agreement and then responded to the collection instrument on the PiperRevised Fatigue Scale. This study corresponds to a cutout of a Master's thesis that was submitted and approved by the Research Ethics Committee (REC) of the Pernambuco Society to Combat Cancer under CAAE No. 45583415.0.3001.5205; and defended by the author by the Associate Nursing Postgraduate Program of the University of Pernambuco / State University of Paraíba (UPE/UEPB), in May 2016.

\section{RESULTS}

The affective dimension of the scale contains items within the range of eight to twelve. It can be seen from table 1 that topic ten, which gives the destructive characteristic of fatigue, revealed the highest mean (6.40) as well as the highest level of fatigue (prevalence) felt by the patients. The ninth question, which confers unacceptable characteristics for fatigue, presented the lowest of the averages (5.82). Item eight of the scale sought to identify the degree of pleasantness of fatigue at the exact moment. With it, it was noticed that only 98 women $(30.9 \%)$ considered their fatigue as more pleasant, having answered values from zero to four. 
Table 1. Mean and Standard Deviation of the Items of the Affective Dimension in Piper Fatigue Scale - Revised. Recife, Pernambuco (PE), Brazil, 2015

\begin{tabular}{|c|c|c|}
\hline ITEMS from Piper-Revised Fatigue Scale Affective Dimension & Mean & Standard deviation \\
\hline 8. How would you describe the fatigue you're feeling right now? (Pleasant/Unpleasant) & 6.14 & 3.39 \\
\hline 9. How would you describe the fatigue you are feeling right now? (Acceptable/Incceptable) & 5.82 & 3.60 \\
\hline 10. How would you describe the fatigue you're feeling right now? (Protective/Destroying) & 6.40 & 3.46 \\
\hline 11. How would you describe the fatigue you are feeling right now? (Positive/Negative) & 6.23 & 3.48 \\
\hline 12. How would you describe the fatigue you're feeling right now? (Normal/Abnormal) & 6.17 & 3.50 \\
\hline Affectivedimension & 6.15 & 2.93 \\
\hline
\end{tabular}

Table 2. How would you describe the fatigue you're feeling right now? Recife, Pernambuco (PE), Brazil, 2015. $(\mathbf{n}=\mathbf{3 1 7})$

\begin{tabular}{lll}
\hline F9 & Frequency & Percentage \\
\hline $0-$ Acceptable & 36 & 11.4 \\
\hline 1 & 21 & 6.6 \\
\hline 2 & 24 & 7.6 \\
\hline 3 & 21 & 6.6 \\
\hline 4 & 17 & 5.4 \\
\hline 5 & 21 & 6.6 \\
\hline 6 & 13 & 4.1 \\
\hline 7 & 27 & 8.5 \\
\hline 8 & 36 & 11.4 \\
\hline 9 & 24 & 7.6 \\
\hline $10-$ Unacceptable & 77 & 24.3 \\
\hline Total & 317 & $100 \%$ \\
\hline Source: Own elaboration. & &
\end{tabular}

Already 219 patients $(69.1 \%)$ responded as the most unpleasant moment fatigue with values from five to ten. It is stressed that $25.6 \%$ of women described their fatigue with the maximum value of the scale, that is, as being unpleasant. In question nine, which investigated the level of acceptance of the fatigue experienced at the time, it was identified that the levels of non-acceptance were mainly those corresponding to the values 8,9 and 10, as identified in table 2 below. The tenth item on the scale measured the degree of protection/destruction fatigue was causing at the time, revealing a significant percentage of women who considered fatigue to be protective. However, there was a predominance of extreme values that characterize the destructive effects of fatigue. In item 11 of the scale, whose objective was to measure the level of positivity/negativity of the fatigue felt at the time, it was observed that 80 patients $(25.2 \%)$ delineated their fatigue as being of a more negative nature, marking, therefore, the maximum extreme (ten) of the series. Measuring the level of normality of the moment's fatigue is topic twelve of the scale. The percentage of women who attributed normality to the feeling of fatigue $(10.1 \%)$ is pointed out as extreme values, while higher values are found in items eight and ten that pointed out abnormality in the level of fatigue.

\section{DISCUSSION}

From the analysis of the affective dimension, it was perceived that fatigue was present in a devastating way in the lives of the women interviewed, which is supported by the high averages acquired by each item of the dimension. For the first three items of this dimension, which investigated how pleasant/displeasing fatigue is, its degree of acceptance, and how protective/destroying it is for these patients, respectively, the response attributed to fatigue as unpleasant, unacceptable, and destructive was predominant. No literature has cited anything similar to these specifically, but these results are understandable since fatigue itself is described as a debilitating symptom of chemotherapy treatment, which makes the patient tired, exhausted, frail and fed up, and is therefore unpleasant, unacceptable and destructive. Item 11, in turn, revealed that the women interviewed considered their level of fatigue to be something negative. The Mansano-Schlosser and Ceolim (2014) study, however, pointed out that most people with cancer aged 60 years or more (age group that fits the prevalence of this study), for example, thought that their health states, including effects such as fatigue, were something very good or positive, since it probably came from the disease itself.

The last item of this dimension found that there was a predominance of the interviewees in stating that they considered such an abnormal intensity of fatigue, since it went as far as to extrapolate all the possible limits of the sensation of fatigue. Mansano-Schlosser and Ceolim (2014), drew attention, once again, to the fact that, many times, the elderly patient with cancer does not tend to report to professionals symptoms such as fatigue because they consider it as something normal, more related to the aging process. This situation should serve as a warning, as it does not fit as a plausible justification by means of a chemotherapy treatment, which leads to fatigue regardless of the patient's age group. It is also worth noting, therefore, that fatigue was reported as abnormal and intense tiredness by patients of the study byMotaand Pimenta (2002).

\section{Conclusion}

It is concluded that using the Piper scale to assess the affective dimension of fatigue in women undergoing chemotherapy treatment, the results of this study revealed a high level of fatigue, predominantly attributed as unpleasant, unacceptable and destructive. There was a predominance among the interviewees who considered the intensity of fatigue abnormal, as they considered it to be beyond the limits of tiredness. However, the elderly population, consider normal the level of 
fatigue, because they relate the process of aging. In view of this, it is important to stress the importance of carrying out more studies that prove the characterization of fatigue in the lives of women undergoing chemotherapy treatment, with the objective of creating strategies to alleviate the symptoms affected by the treatment, which interfere significantly in the lives of these women.

\section{Aknowledgements}

Acknowledgements of this work go to the patients under treatment approached in interview; as well as to the multiprofessional health care team that was very receptive to us during the performance of this study.

\section{REFERENCES}

Anjos ACY. 2005. A experiência da terapêutica quimioterápica oncológica na visão do paciente. Dissertação (Mestrado) - Escola de Enfermagem de Ribeirão Preto, Universidade de São Paulo, Ribeirão Preto.

Cantinelli FS, Camacjo RS, Smaletz O, Gonsales BK, Braguittoni E, Jr. Rennó J 2006. A oncopsiquiatria no Câncer de mama: considerações a respeito de questões do feminino. Rev. Psiquiatr. Clin. 33(3):124-133. Avaliable from:http://www.scielo.br/pdf/rpc/v33n3/a02v33n3.pdf.

Jemal A, Bray F, Center MM, Ferlay J, Ward E, Forman D. 2011. Global cancer statistics. CA Cancer J Clin, n. 61:6990. Doi: $10.3322 /$ caac. 20107 .
Lamino DA. 2012. Prevalência e fatores associados à fadiga em mulheres com câncer de mama. Dissertação (Mestrado) - Escola de Enfermagem da Universidade de São Paulo, São Paulo.

Lisboa LF. 2009. Tendências da incidência e da mortalidade do câncer de mama feminino no município de São Paulo. Dissertação (Mestrado) - Faculdade de Saúde Pública da Universidade de São Paulo, São Paulo.

Mansano-Schlosser TC,Ceolim MF 2014. Fadiga em idosos em tratamento quimioterápico. Revista Brasileira de Enfermagem. 67(4):623-639.

Mota DDCF, Pimenta CAM 2002. Fadiga em pacientes com câncer avançado: conceito, avaliação e intervenção. Revista Brasileira de Cancerologia. 48(4):577-583.

Mota DDCFF, Pimenta CAM, Piper BF 2009. Fatigue in Brazilian cancer patients, caregivers, and nursing students: a psychometric validation study of the Piper Fatigue ScaleRevised. Suport Care Cancer. 17:645-652.

National Comprehensive Cancer Network (NCCN) 2011. Clinical Practice Guidelines in Oncology (NCCN Guidelines $^{\mathrm{TM}}$ ) Cancer Related-fatigue, version 1.

Silva MD. 2013. As repercussões corporais vivenciadas pela mulher com câncer de mama decorrentes do tratamento quimioterápico: uma análise à luz da Teoria de SisterCallista Roy. Dissertação (Mestrado) - Faculdade de Enfermagem da Universidade do Estado do Rio de Janeiro, Rio de Janeiro. 